\title{
Direct Measurements, Numerical Predictions and Simple Formula Estimations of Welding-Induced Biaxial Residual Stresses in a Full-Scale Steel Stiffened Plate Structure
}

Myung Su Yia , Sung Hwan Noh ${ }^{\mathrm{a}}$, Dong Hun Lee ${ }^{\mathrm{a}}$, Dong Houi Seo ${ }^{\mathrm{a}}$ and Jeom Kee Paik ${ }^{a, b, c^{*}}$

a Department of Naval Architecture and Ocean Engineering, Pusan National University, South Korea; ${ }^{b}$ The Korea Ship and Offshore Research Institute (The Lloyd's Register Foundation Research Centre of Excellence), Pusan National University, South Korea; ${ }^{\mathrm{c}}$ Department of Mechanical Engineering, University College London, UK

*Corresponding author. J.K. Paik. Email. j.paik@ucl.ac.uk

\begin{abstract}
As a sequel to another paper of the authors on welding-induced initial deformations [1], this paper aims to obtain a direct measurement database of welding-induced residual stresses in a full-scale steel stiffened plate structure and also to study the applicability of computational models to predict them. A full-scale steel stiffened plate structure in association with plate panels in bottom structures of an as-built containership carrying 1,900 TEU was fabricated using exactly the same welding technology as used in today's shipbuilding industry. The X-ray diffraction method was employed to measure the residual stress distributions in the plating. In addition to simple formula estimations, computational models using the three-dimensional thermo-elastic-plastic finite element method were applied to predict the residual stress distributions. A comparison between full-scale measurements, numerical predictions and simple formula estimations was made. Details of the full-scale measurements are documented as they can be useful to validate the computational models formulated by other researchers.
\end{abstract}

Keywords: Steel stiffened plate structures, welding-induced residual stresses, full-scale measurements, three-dimensional thermo-elastic-plastic finite element method, X-ray diffraction method, simple formula estimations

\section{Introduction}

Stiffened panels are used in naval, mechanical and civil engineering structures as primary strength parts of ships, ship-shaped offshore installations and bridges which should sustain external forces with tolerance arising from operational and environmental conditions, as shown in Figure 1. Support members (longitudinal stiffeners and transverse frames) are attached to plating by fillet welding, and pieces of plate sheets are connected by butt welding. Stresses occurred in the process of heating and cooling of welding do not disappear even after fabrication is completed, where tensile residual stress block develops around weld line (heat-affected zone) and 
compressive residual stress block appears in the remaining part of plating so as to keep an equilibrium condition between tensile and compressive stresses, as shown in Figure 2 [2]. It is important to realize that welding-induced residual stresses develop in both the length and breadth directions of plating as welding is applied to attach both longitudinal stiffeners and transverse frames, as shown in Figure 3 [3].

Welding-induced residual stresses affect buckling and ultimate strength of plate panels which is primary strength criteria for structural analysis and design. Thin-plated structures (e.g., accommodation structures and deck houses of ships or offshore platforms) sometimes buckle with significant distortions during fabrication which require costly fairing works. This is often recognized as thermal plate buckling phenomenon and it can be prevented or controlled if the welding-induced residual stresses can be predicted quickly and accurately [4].

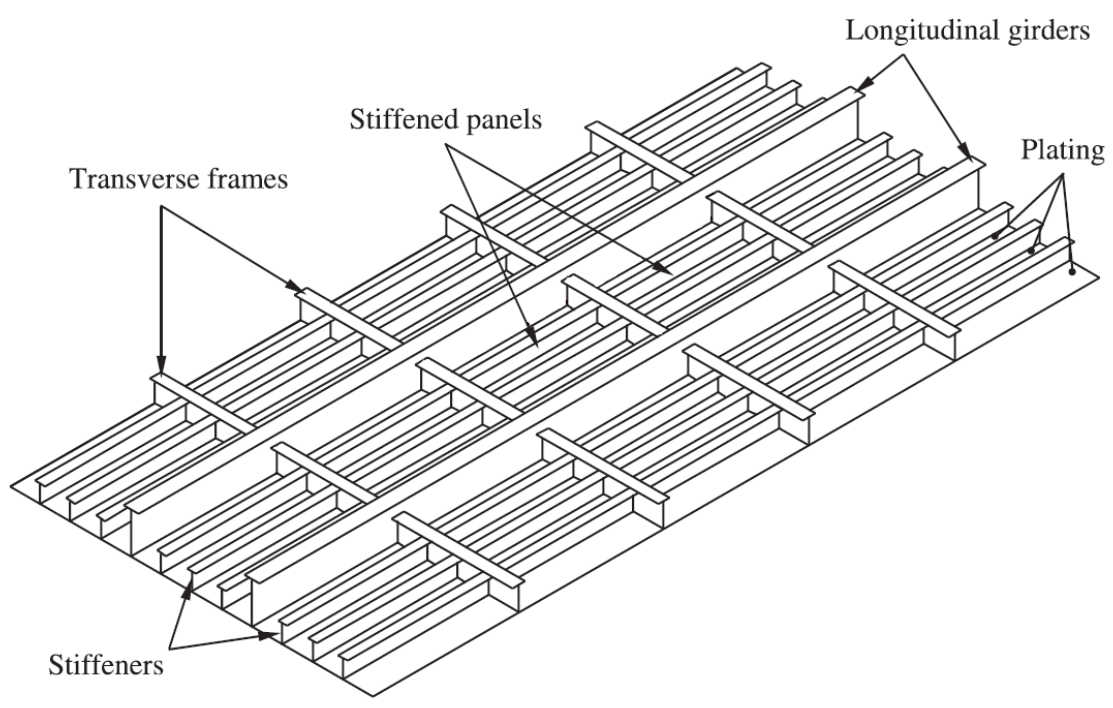

Figure 1. The stiffened plate structure [3].
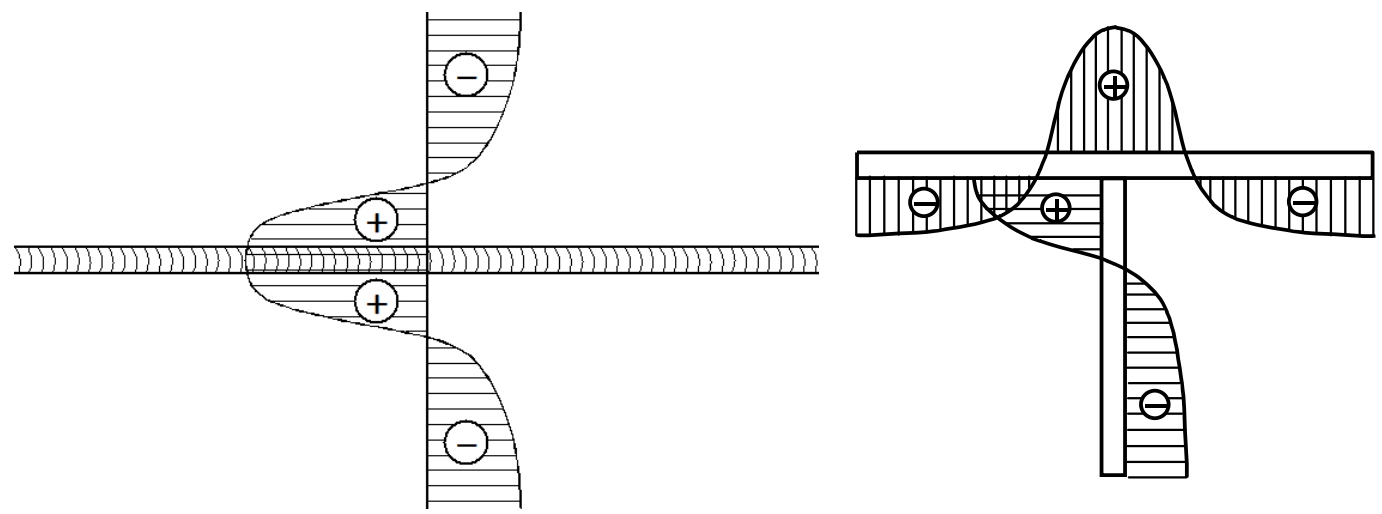

Figure 2. Tensile (+) and compressive (-) residual stresses in a butt welded plate and a fillet-welded panel [3]. 


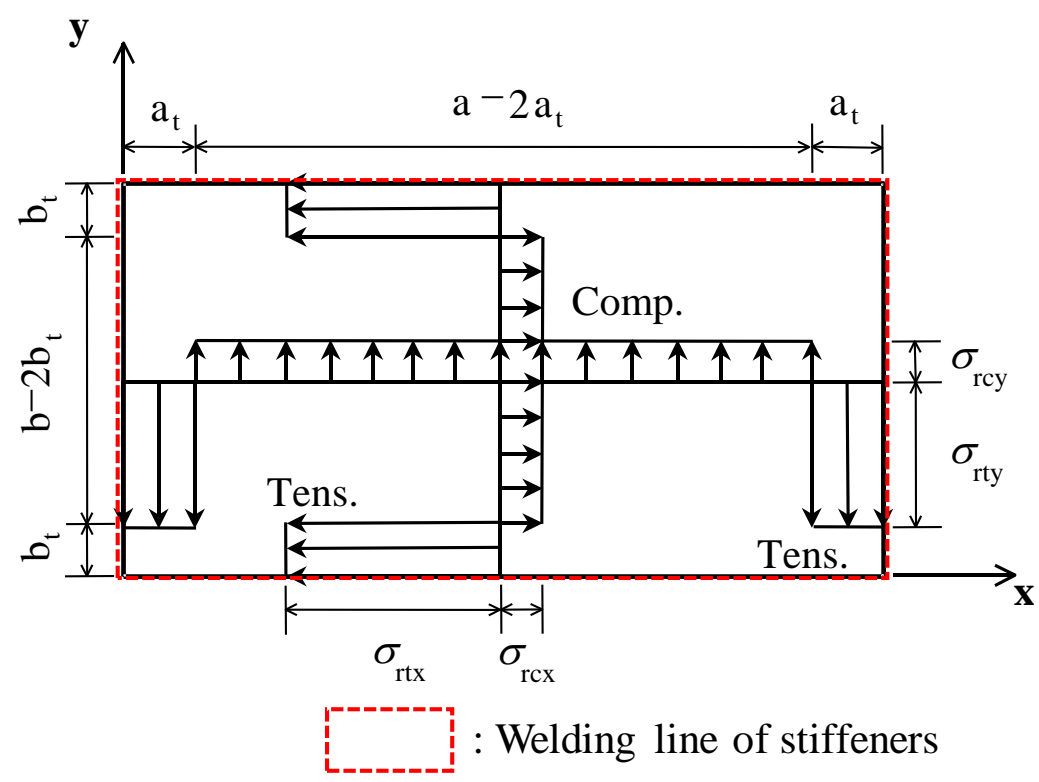

Figure 3. Idealized pattern of welding-induced residual stresses in both the plate length $(x)$ and breadth $(y)$ directions [3].

During past several decades, the importance of characterizing welding-induced residual stresses in plate panels has been well recognized, and a large number of studies in numerical predictions and direct measurements are available in the literature. Studies of numerical predictions on welding-induced residual stresses of steel- and aluminum-plated structures include Masubuchi [5], Smith et al. [6], Paik and Pedersen [7], Ueda [2], Paik et al. [8-11], Paik [12-15], Vhanmane and Bhattacharya [16], Luís et al. [17], Bruno et al. [18], Khan and Zhang [19], Eggert et al. [20], Gannon et al. [21-23], Khedmati et al. [24], Teresa and Craig [25], Iranmanesh et al. [26], Farajkhah et al. [27], Fu et al. [28], Lillemäe et al. [29] and Chen et al. [30]. Studies of direct measurements include Masubuchi [5], Matsui [31], Smith et al. [6], Cheng et al. [32], Ueda [2], and Kenno et al. [33, 34].

Despite that the importance of direct measurements has been realized, the databases of direct measurements are still lacking in the literature, and moreover most of them have been obtained on small-scale structure models which cannot be directly related to full-scale structures because adequate scaling laws are unavailable. It is therefore needed to develop measurement database of welding-induced residual stresses on full-scale stiffened plate structures which can minimize unwanted uncertainties due to scale effects.

The aim of the present paper is to contribute to developing measurement data of welding-induced residual stresses in both the plate length and breadth directions of a full-scale steel stiffened plate structure. This paper is associated with a series of full-scale physical tests on the ultimate strength under lateral patch loading in fires without passive fire protection in transverse frames [35], under lateral patch loading in fires with passive fire protection in transverse frames [36], under cyclic axial-compressive loading [37], at cryogenic condition with a temperature of $-160^{\circ} \mathrm{C}$ 
[38], and at a temperature of $-80^{\circ} \mathrm{C}$ [39]. The data of direct measurements for welding-induced initial deformations in the same test structure was also obtained and reported in a separate paper [1].

Computational models for predicting welding-induced residual stresses in the test structure were developed using three-dimensional thermo-elastic-plastic finite element method, and simple formulations were also used to estimate them. A comparison between direct measurements, numerical predictions and simple formula estimations was made. Details of direct measurements are documented in a tabulated form, which will be useful to validate computational models developed by other researchers.

\section{Design and fabrication of a full-scale steel stiffened plate structure}

Bottom plate panels of an as-built containership carrying 1,900 TEU were selected for the present study as shown in Figure 4. Dimensions of the structure are presented in Figure 5. With the nomenclature of structural scantlings shown in Figure 6, Table 1 lists its dimensions in detail.

The material is high tensile steel with grade AH32. After material procurement, tensile coupon test specimens were extracted from the steel sheet as per ASTM E8 specifications [40], as shown in Figure 7(a). The tensile coupon testing was continued until it was separated into two pieces as shown in Figure 7(b). Three specimens were tested, realizing almost identical results of the engineering stress-engineering strain curve as shown in Figure 8. Table 2 summarizes the mechanical properties of the material AH32 obtained from the tensile coupon tests.
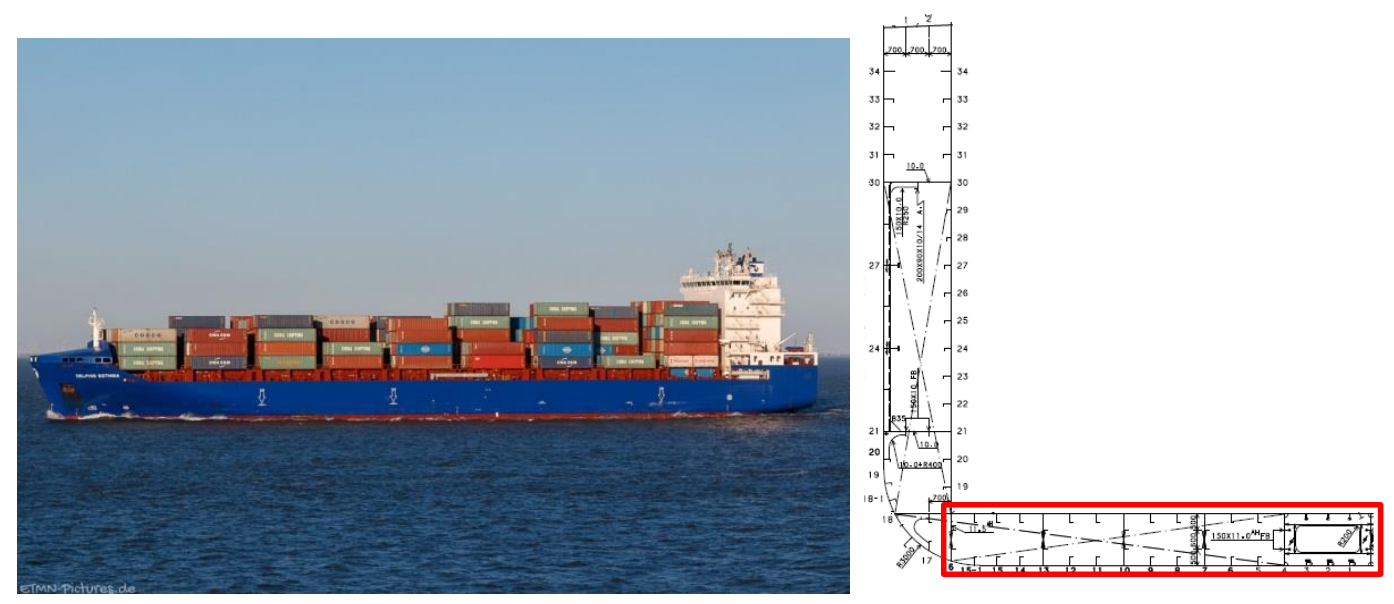

Figure 4. Stiffened panels in bottom structures of an as-built 1,900 TEU containership. 


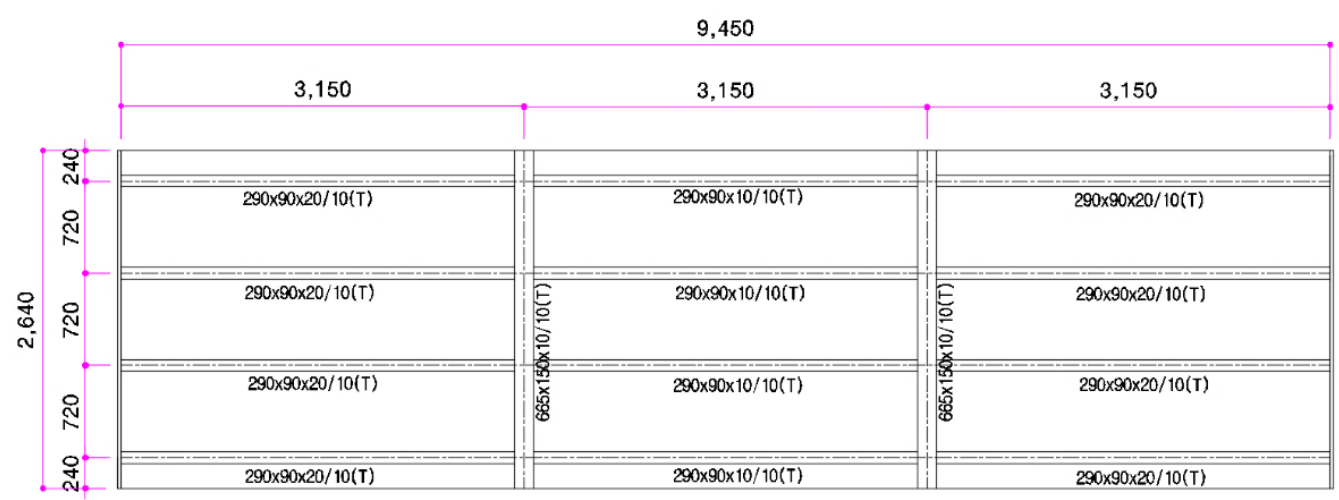

Figure 5. Dimensions of the tested structure.

(a)

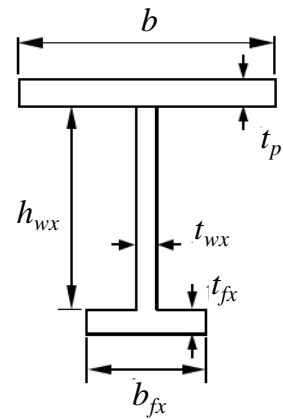

(b)

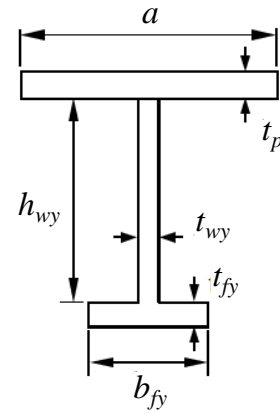

Figure 6. Nomenclature of dimensions for (a) the longitudinal stiffeners and (b) the transverse frames.

Table 1. Dimensions of the tested structure.

\begin{tabular}{|c|c|c|c|c|c|c|c|c|}
\hline \multicolumn{3}{|c|}{ Plate (mm) } & \multicolumn{6}{c|}{ Support member (mm) } \\
\hline$a$ & $b$ & $t$ & \multicolumn{2}{|c|}{ Type } & $h_{w}$ & $t_{w}$ & $b_{f}$ & $t_{f}$ \\
\hline \multirow{2}{*}{3,150} & 720 & \multirow{2}{*}{10} & $\begin{array}{c}\text { Longitudinal } \\
\text { stiffener }\end{array}$ & Center & 290 & 10 & 90 & 10 \\
\cline { 5 - 10 } & & & $\begin{array}{c}\text { Transverse } \\
\text { frame }\end{array}$ & - & 665 & 10 & 150 & 10 \\
\hline
\end{tabular}

Note: $a=$ plate length (spacing between transverse frames), $b=$ plate breadth (spacing between longitudinal stiffeners), $t=$ plate thickness, $h_{w}=$ height of web,

$t_{w}=$ thickness of web, $b_{f}=$ breadth of flange, and $t_{f}=$ thickness of flange. 
(a)
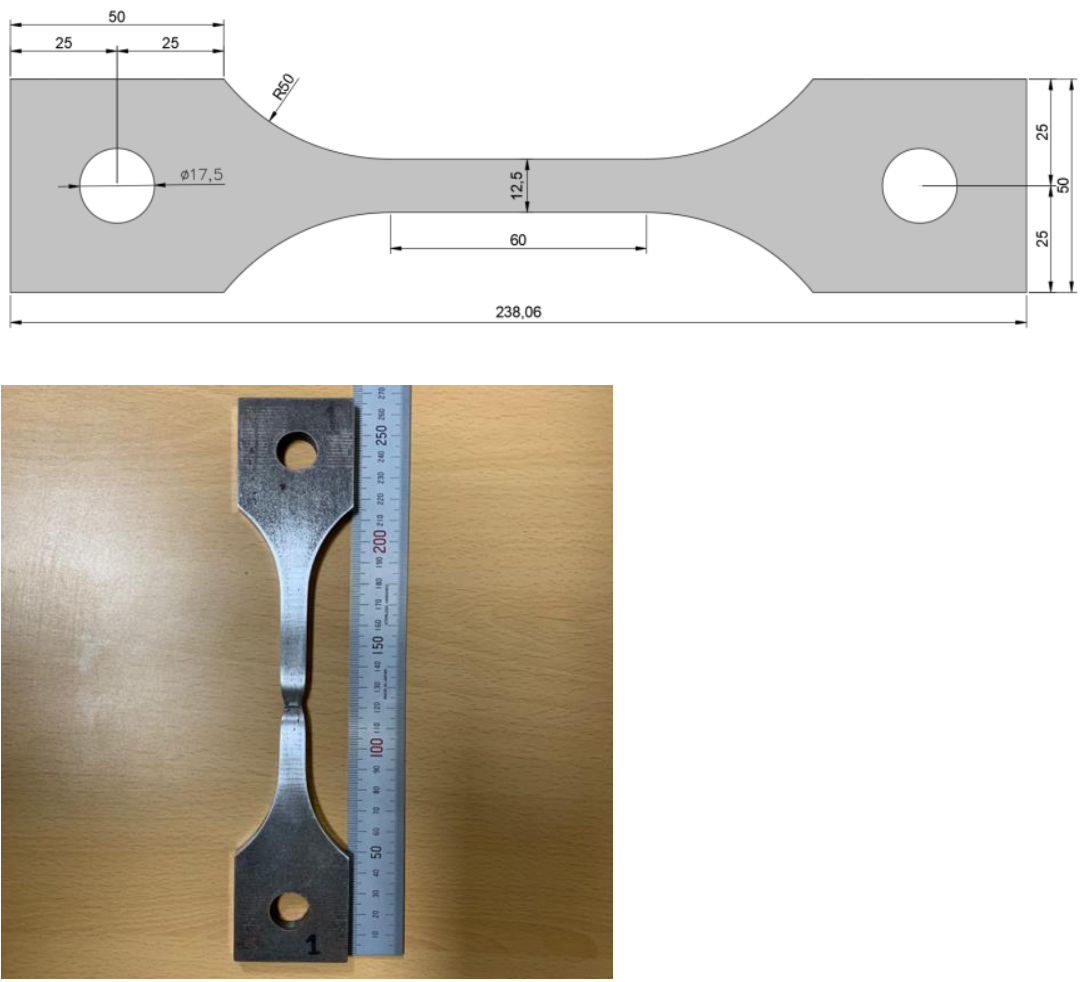

Figure 7. Tensile coupon test specimens for material AH32: (a) dimensions of the specimen, (b) specimen after tensile coupon test.

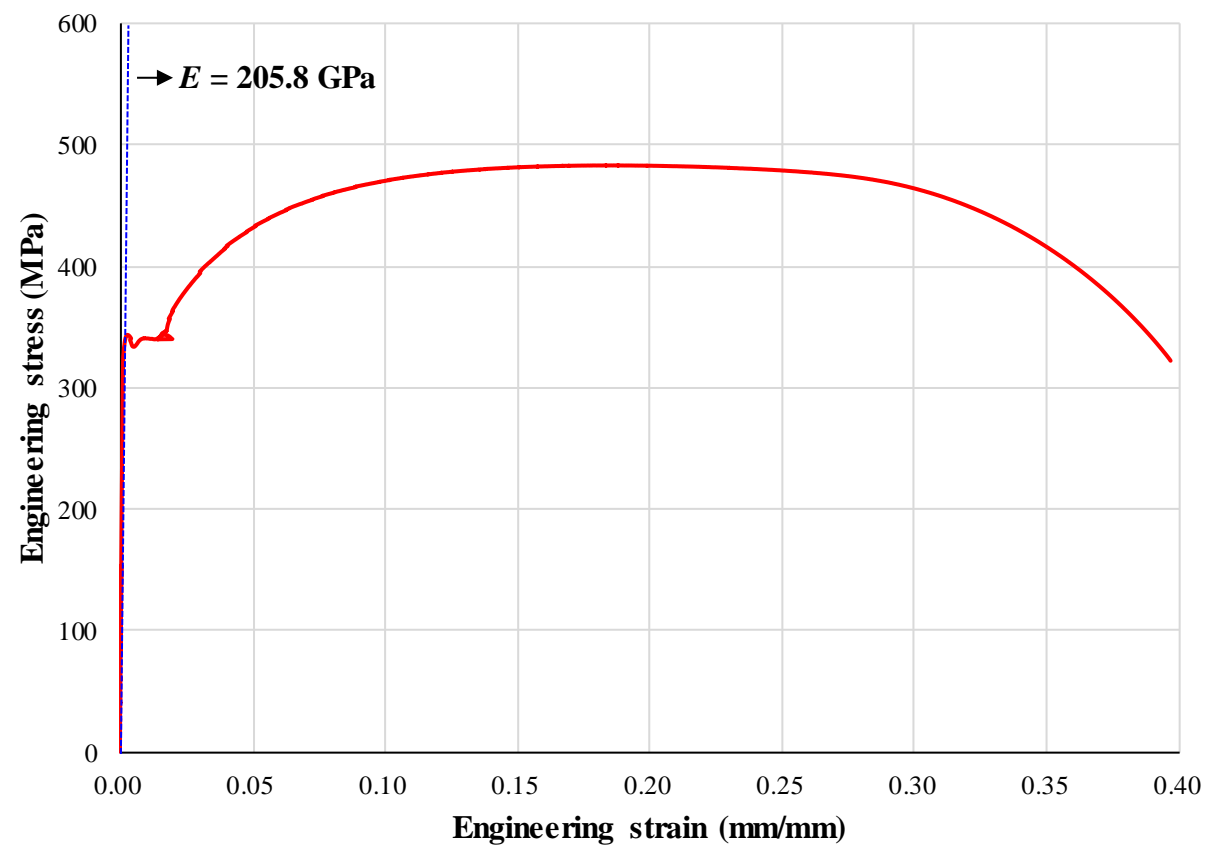

Figure 8. Obtained engineering stress versus engineering strain curve of the material AH32. 
Table 2. Obtained mechanical properties of the AH32 high tensile steel.

\begin{tabular}{|c|c|c|c|c|}
\hline$E(\mathrm{GPa})$ & $\sigma_{Y}(\mathrm{MPa})$ & $\sigma_{T}(\mathrm{MPa})$ & $v$ & $\varepsilon_{f}(\%)$ \\
\hline 205.8 & 331 & 483 & 0.3 & 40.0 \\
\hline
\end{tabular}

Note: $E$ = elastic modulus, $\sigma_{Y}=$ yield strength, $\sigma_{T}=$ ultimate tensile strength,

$v=$ Poisson's ratio, and $\varepsilon_{f}=$ fracture strain (elongation).

The structure was fabricated in a shipyard, Busan, South Korea. Exactly the same technology of welding was applied as used in today's shipbuilding industry following the classification rules [41]. The steel sheet procured was large enough to build the structure without butt-welds to connect pieces of plate sheets. Fillet welding using FCAW (flux-cored arc welding) technique was applied to attach longitudinal stiffeners and transverse frames to plating. It is confirmed that the applied conditions of welding met the WPS (welding procedure specifications) as indicated in Table 3. It is also confirmed that the fillet weld was applied with full penetration with a leg length of $7 \mathrm{~mm}$, as shown in Figure 9.

Table 3. Welding parameters applied for fabrication of the structure.

\begin{tabular}{cccccc}
\hline $\begin{array}{c}\text { Welding } \\
\text { parameter }\end{array}$ & Current(A) & Voltage(V) & Speed(cm/min) & $\begin{array}{c}\text { Heat input } \\
(\mathrm{KJ} / \mathrm{cm})\end{array}$ & $\begin{array}{c}\text { Leg } \\
\text { length } \\
(\mathrm{mm})\end{array}$ \\
\hline WPS & $225-275$ & $23-32$ & $24-34$ & $7-18$ & 7 \\
Application & 260 & 28 & 30 & 14.56 & 7 \\
\hline
\end{tabular}

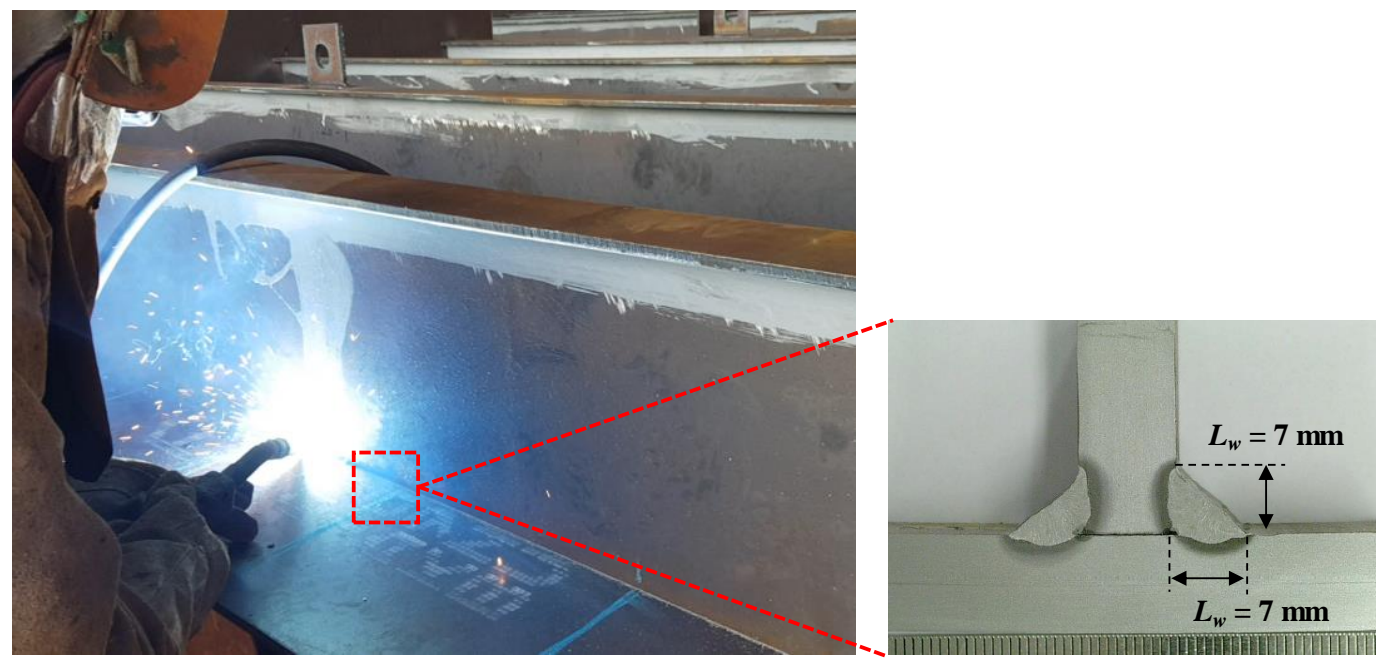

Figure 9. Full penetration of fillet weld with a leg length of $7 \mathrm{~mm}$. 

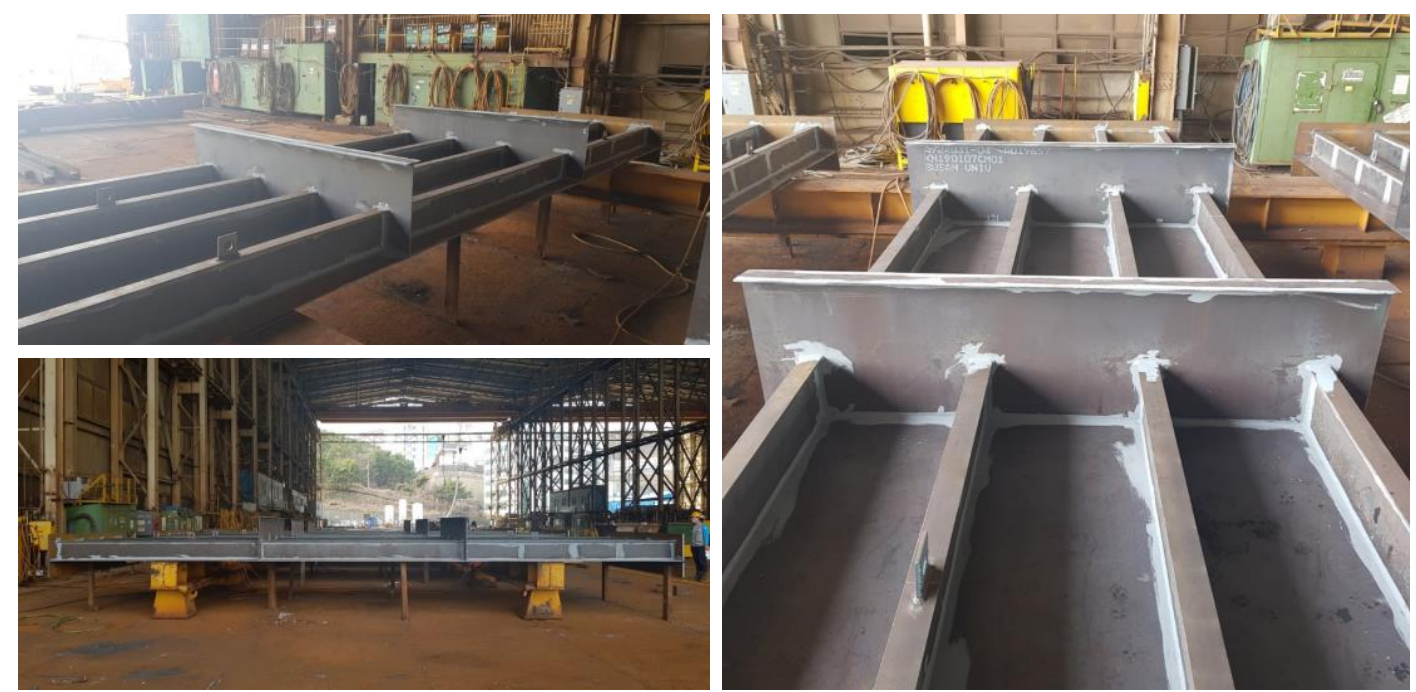

Figure 10. The full-scale steel stiffened plate structure after completion of fabrication in the shipyard.

\section{Measurements of welding-induced residual stresses}

A non-destructive technique, the X-ray diffraction (XRD) method was used to measure welding-induced residual stresses in the structure. Table 4 indicates the details of the measuring tool called Xstress3000 ${ }^{\mathrm{TM}}$ [42]. Figure 11 shows the measurement of welding-induced residual stresses using the XRD tool.

Table 4. Details of the XRD tool used for measuring welding-induced residual stresses.

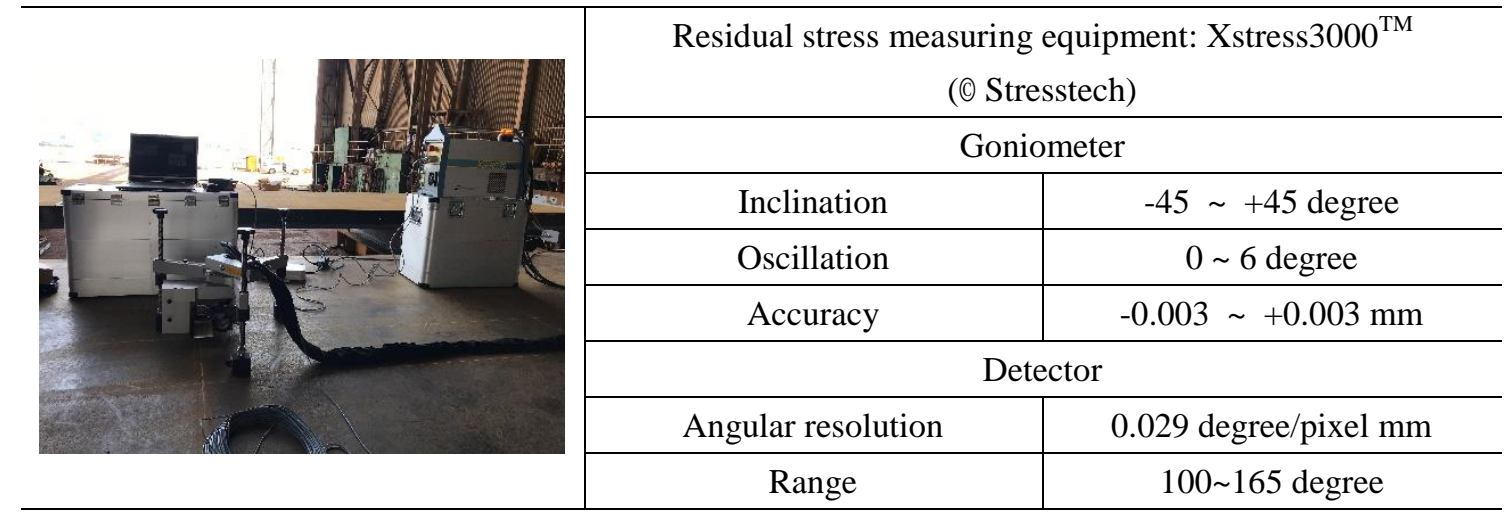



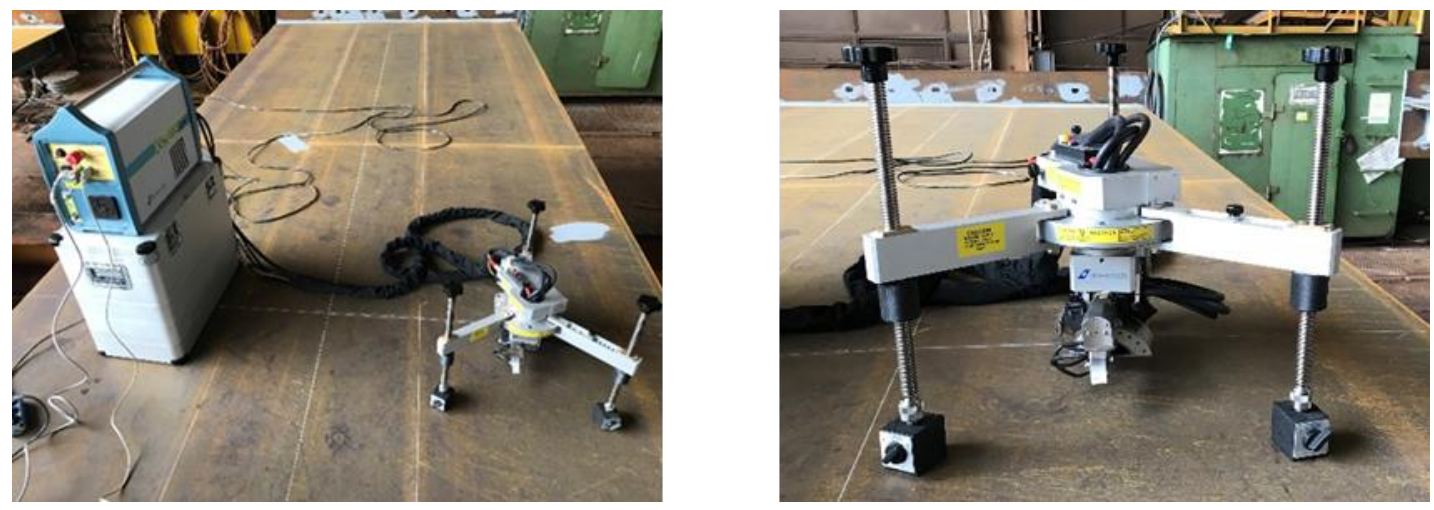

Figure 11. Measurement of welding-induced residual stresses using the XRD tool.

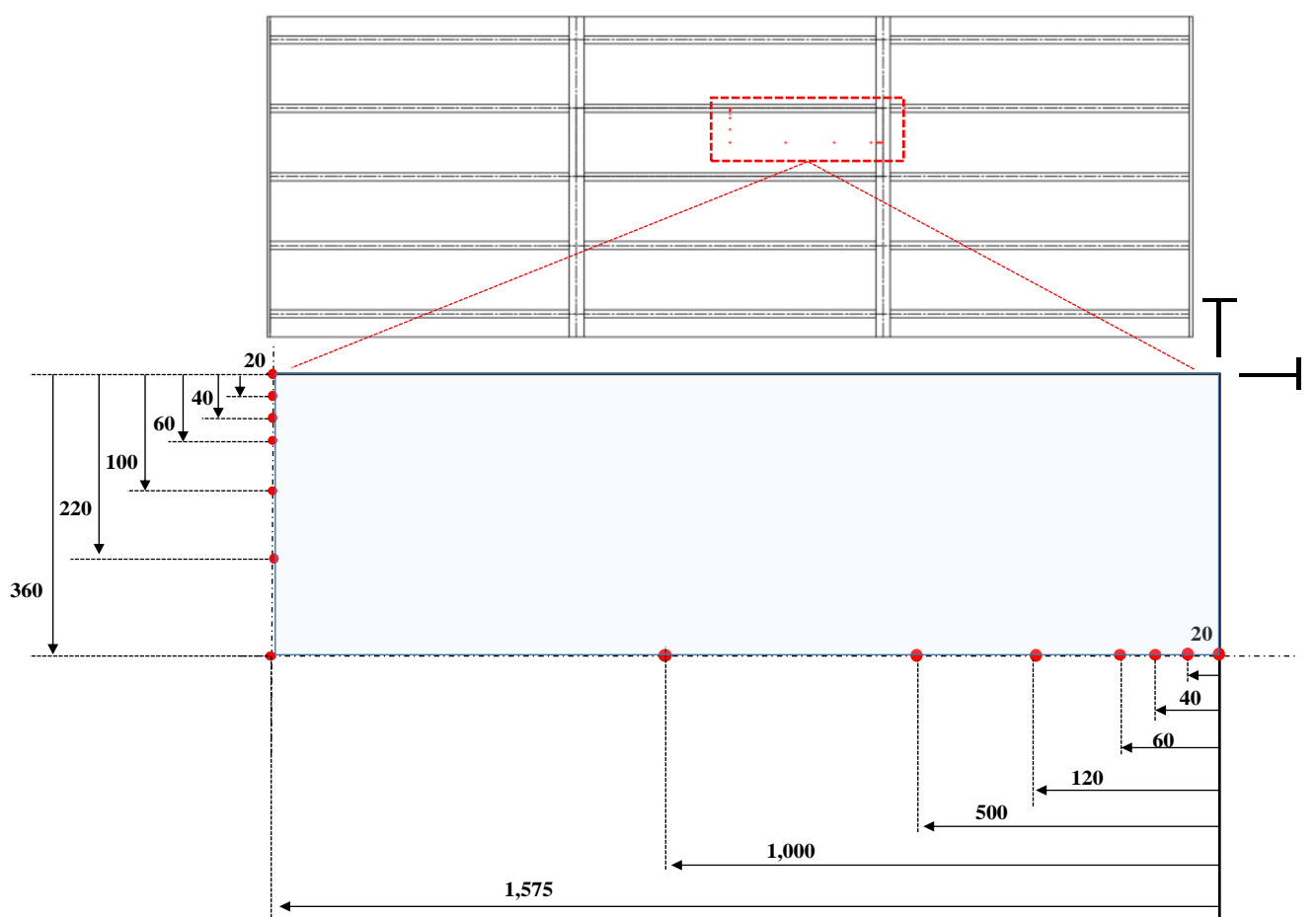

Figure 12. Monitoring (measuring) points.

Measuring (monitoring) points can be defined at locations of interest as shown in Figure 12. As welding-residual stresses develop in both the plate length and breadth directions, the measuring points were allocated in both directions. Also, the distribution of residual stresses in the heat-affected zone is usually changing rapidly, and thus a more number of monitoring points at a smaller interval of measurements were arranged. It is recognized that the distribution of welding-induced residual stresses is almost symmetric with respect to the center line of the plate length or breadth [2], and thus the measuring points were allocated only at a half of the plate length or breadth. Also, biaxial tensile residual stresses may develop in the plate corner or at the junction of the longitudinal stiffeners and transverse frames as shown in Figure 3 although they were not measured because it was difficult to set up the XRD tool around the plate corner. 
Residual stresses are distributed as illustrated in Figures 13 and 14. Table 5 tabulates the measured data, where + indicates tensile residual stress and - indicates compressive residual stress. It is observed that tensile residual stresses develop around the heat-affected zone, and compressive residual stresses develop in the middle of plating. The tensile residual stresses can be as high as $90 \%$ of material yield strength. The breadth of tensile residual stress block is about $40 \mathrm{~mm}$ in both directions. Also, the compressive residual stresses in the longitudinal (plate length) direction are greater than those in the transverse (plate breadth) direction. This is because the internal forces associated with the breadth of tensile residual stress block are almost the same each other, but the plate length is 4.375 times the plate breadth and subsequently the equilibrium condition between tensile and compressive residual stress blocks results in the smaller compressive stresses in the plate breadth (transverse) direction.

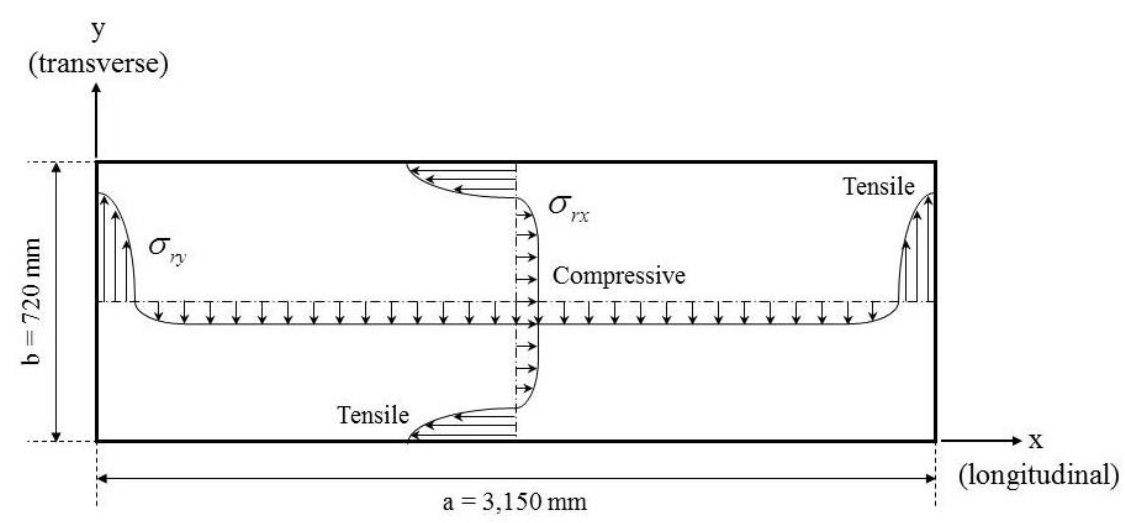

Figure 13. Residual stresses distrubution in plating.

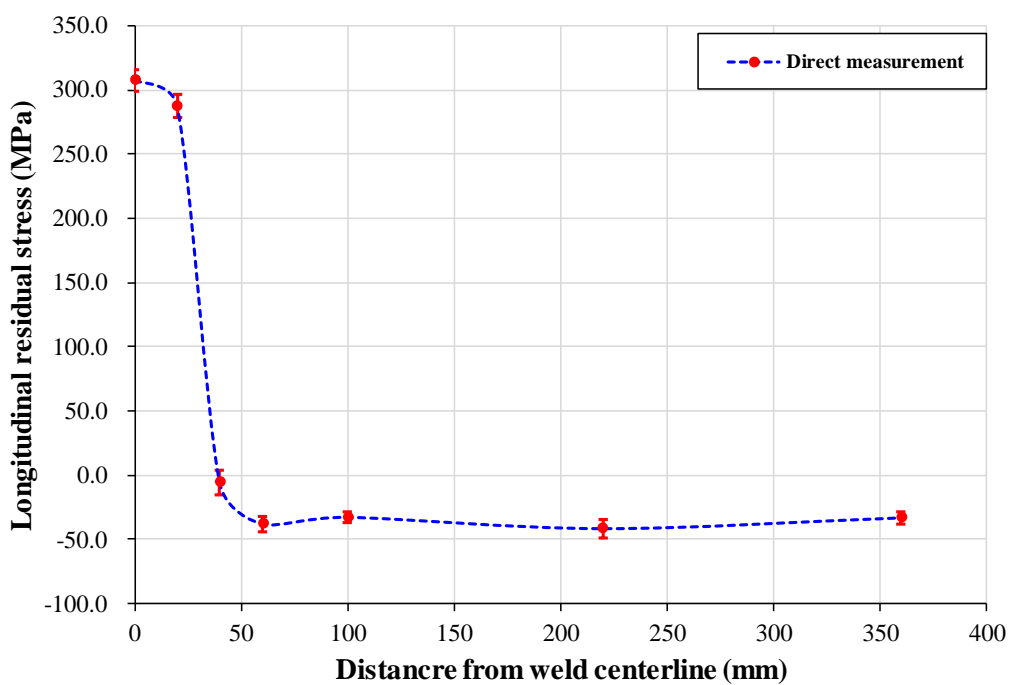

(a) 


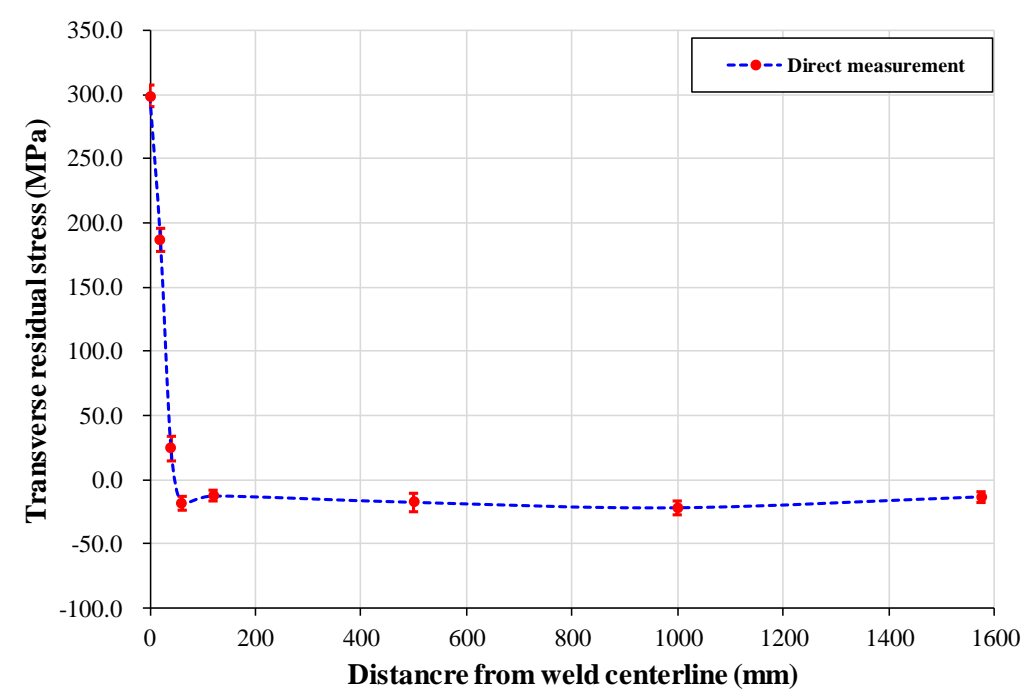

(b)

Figure 14. Distribution of welding-induced residual stresses (a) plate length (longitudinal) direction, (b) plate breadth (transverse) direction.

Table 5. Measured data of welding-induced residual stresses.

\begin{tabular}{|c|c|c|c|c|c|}
\hline $\begin{array}{c}\text { Distance } \\
\text { from weld } \\
\text { center line } \\
(\mathrm{mm})\end{array}$ & $\sigma_{r x}(\mathrm{MPa})$ & \pm Error(MPa) & $\begin{array}{c}\text { Distance } \\
\text { from weld } \\
\text { center line } \\
(\mathrm{mm})\end{array}$ & $\sigma_{r y}(\mathrm{MPa})$ & \pm Error(MPa) \\
\hline 0 & +307.5 & 8.5 & 0 & +298.7 & 8.2 \\
\hline 20 & +287.6 & 10.3 & 20 & +187.0 & 9.3 \\
\hline 40 & -5.7 & 3.0 & 40 & +24.6 & 9.3 \\
\hline 60 & -38.1 & 11.9 & 60 & -18.3 & 5.9 \\
\hline 100 & -32.9 & 8.2 & 120 & -12.7 & 4.1 \\
\hline 220 & -41.7 & 11.2 & 500 & -17.6 & 7.1 \\
\hline 360 & -33.3 & 4.2 & 1000 & -21.8 & 5.3 \\
\hline- & - & - & 1575 & -13.3 & 4.2 \\
\hline
\end{tabular}

Note. $\sigma_{r x}$ is the residual stress in the plate length (longitudinal) direction, $\sigma_{r y}$ is the residual stress in the plate breadth (transverse) direction, and \pm Error indicates the possible errors of measurements due to the accuracy of the XRD tool.

\section{Numerical predictions of welding-induced residual stresses}

Three-dimensional thermo-elastic-plastic finite element method was applied to predict the welding-induced residual stress distributions. Details of the computational models and approaches are described in a separate paper of the authors [43]. Here only the results of computational models together with computed values are presented.

Figure 15 shows the finite element method model for a quarter of the structure with 
symmetric conditions. The structure was modeled using 8-node 3D brick thermo-elastic-plastic finite elements (full integration type elements) which took into account the effects of plasticity, hyper-elasticity, stress stiffening, creep, large deflection and large strain. The order of welds is indicated in Figure 15. The same parameters of heat sources as used for fabrication indicated in Table 3 were applied in the numerical predictions.

Figure 16 shows the distribution of temperatures with moving heat sources obtained from the computations. Figure 17 shows von Mises stress distribution after the $1^{\text {st }}$ weld and cooling process was completed. Figure 18 shows the computed results of welding-induced residual stresses in the plate length and breadth directions. Figure 19 compares the welding-induced residual stresses in plating between direct measurements and numerical predictions. It is found that the computational models provide reasonable solutions of welding-induced residual stress distributions compared to the measurements.

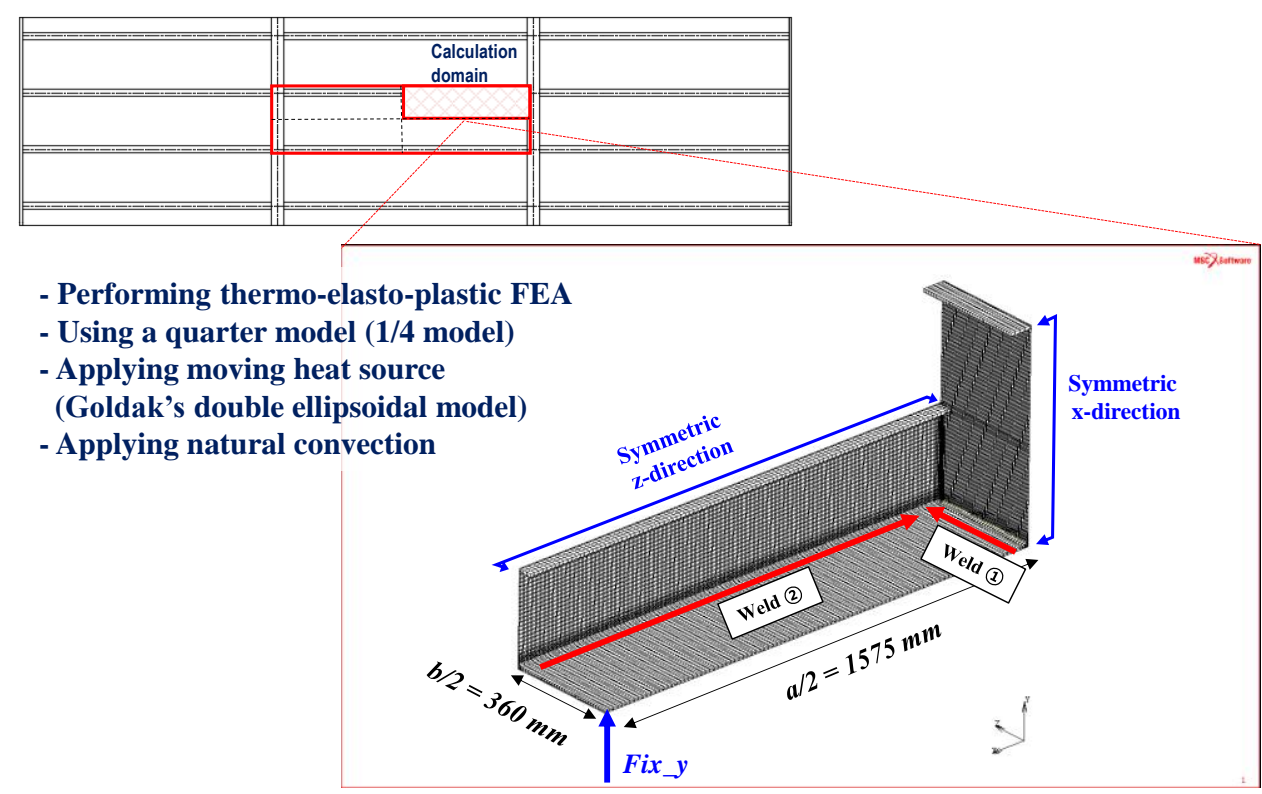

Figure 15. Finite element method model for a quarter model of the structure.

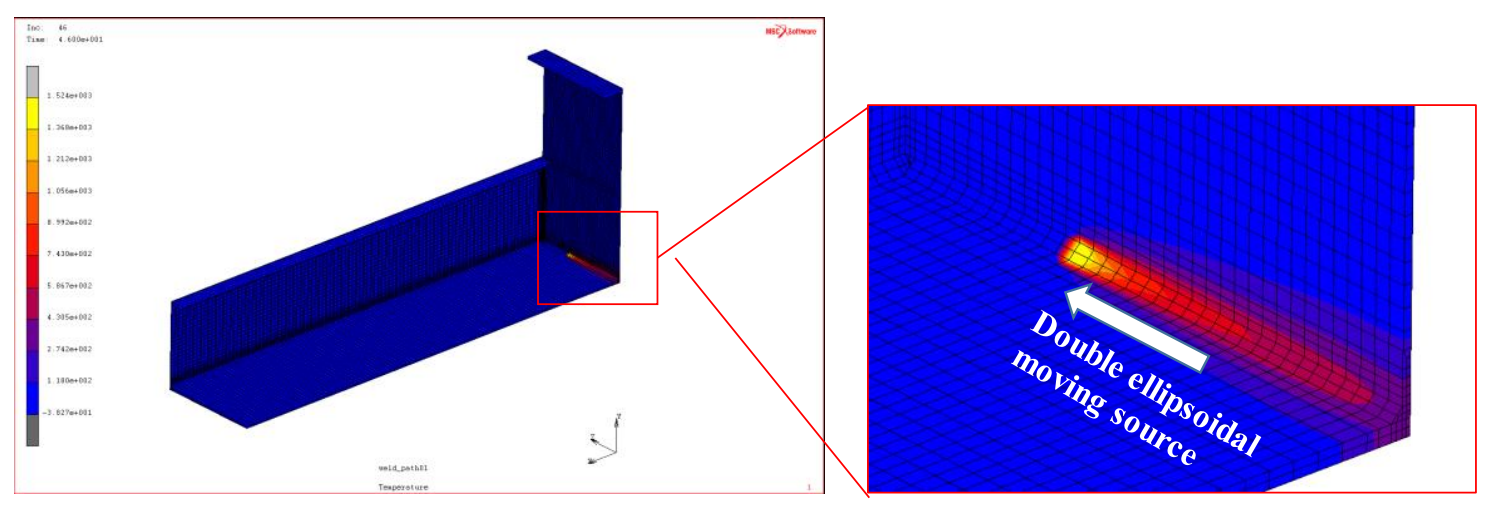

Figure 16. Temperature distribution with moving heat source in the first weld zone. 


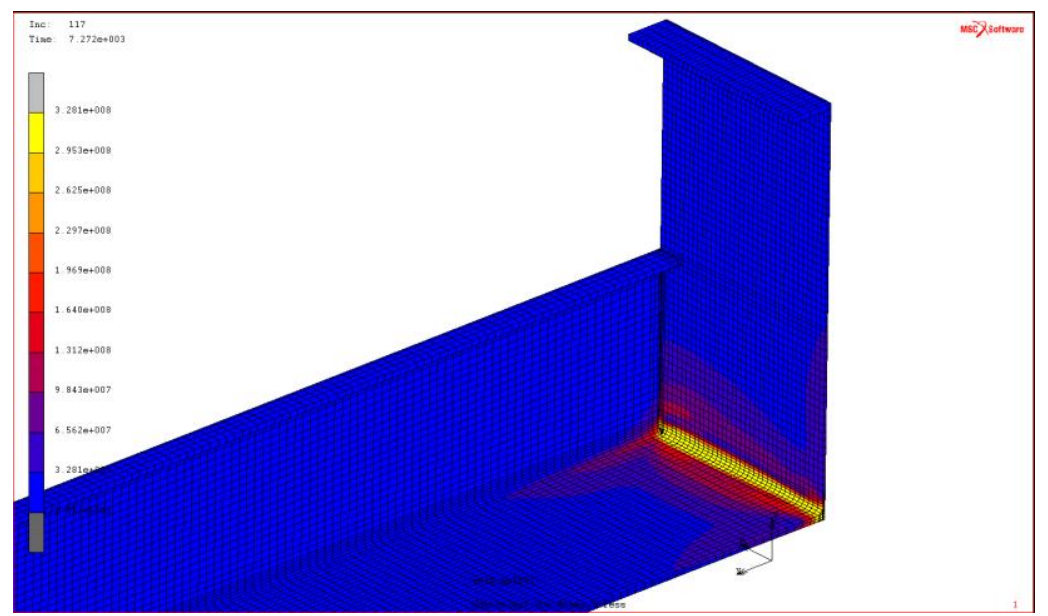

Figure 17. von Mises stress distribution after completing $1^{\text {st }}$ weld and cooling process.

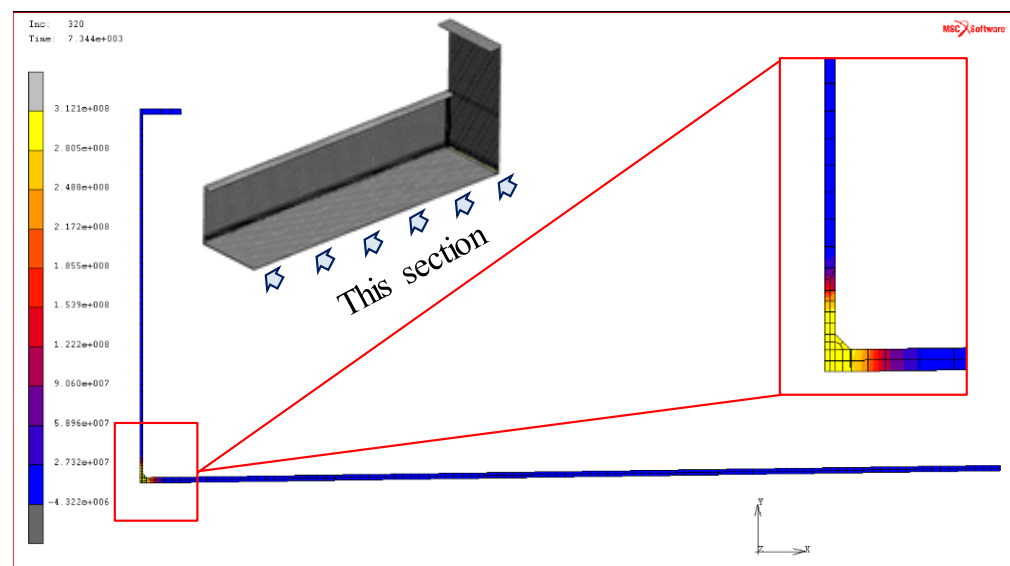

(a)
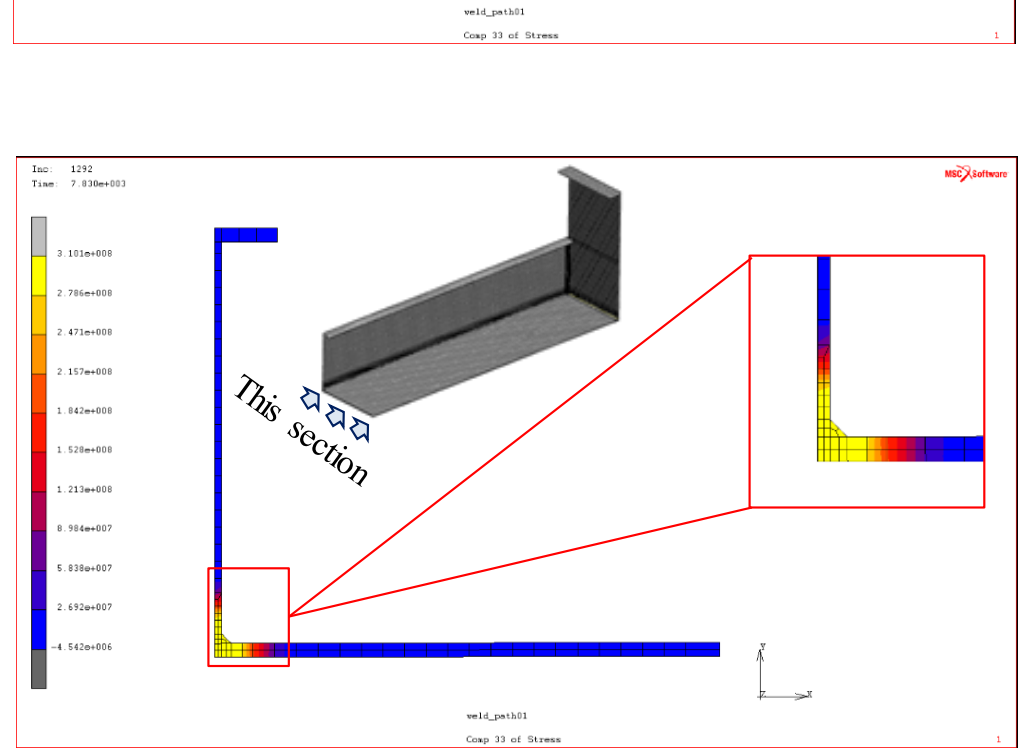

(b)

Figure 18. Numerical predictions of welding-induced residual stresses in (a) the plate length (longitudinal) direction, (b) the plate breadth (transverse) direction. 


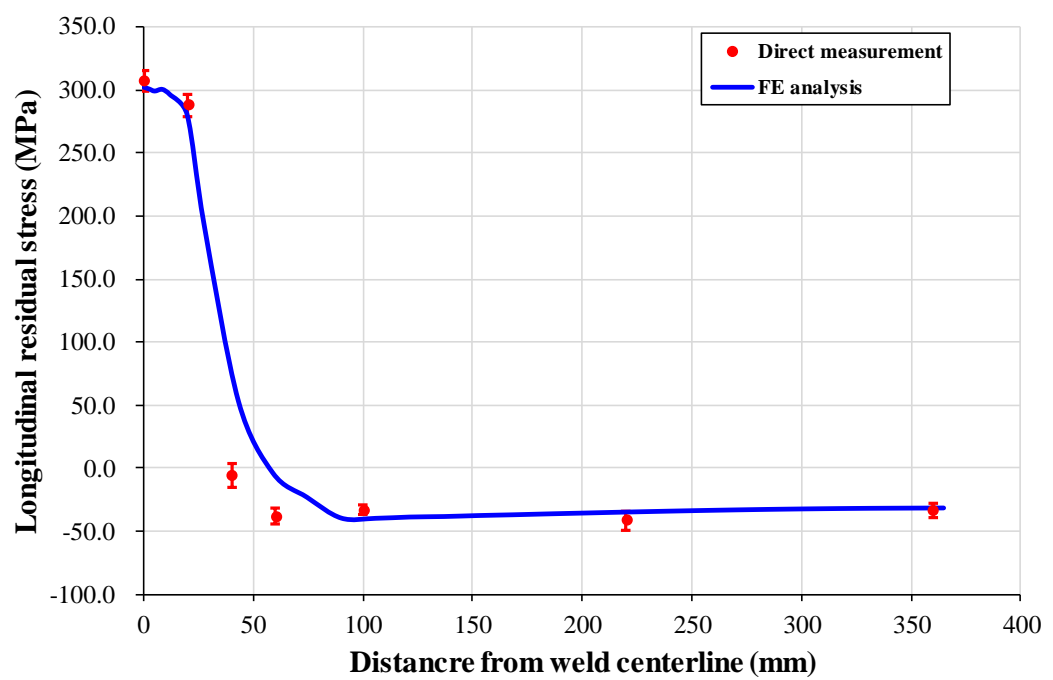

(a)

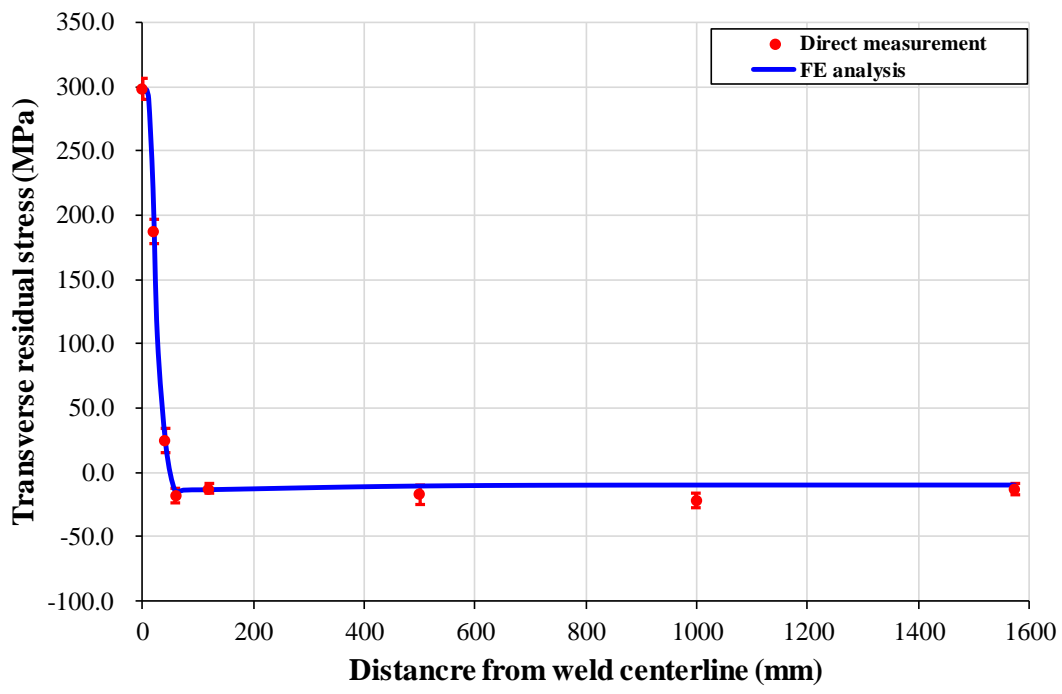

(b)

Figure 19. Comparison of welding-induced residual stresses between direct measurements and numerical predictions.

Figure 20 shows the statistical error assessment between direct measurements and numerical computations in plate residual stresses. The mean value and standard deviation are 0.867 and 0.411 , respectively in the plate length (longitudinal) direction, and 1.150 and 0.201 , respectively in the plate breadth (transverse) direction. 


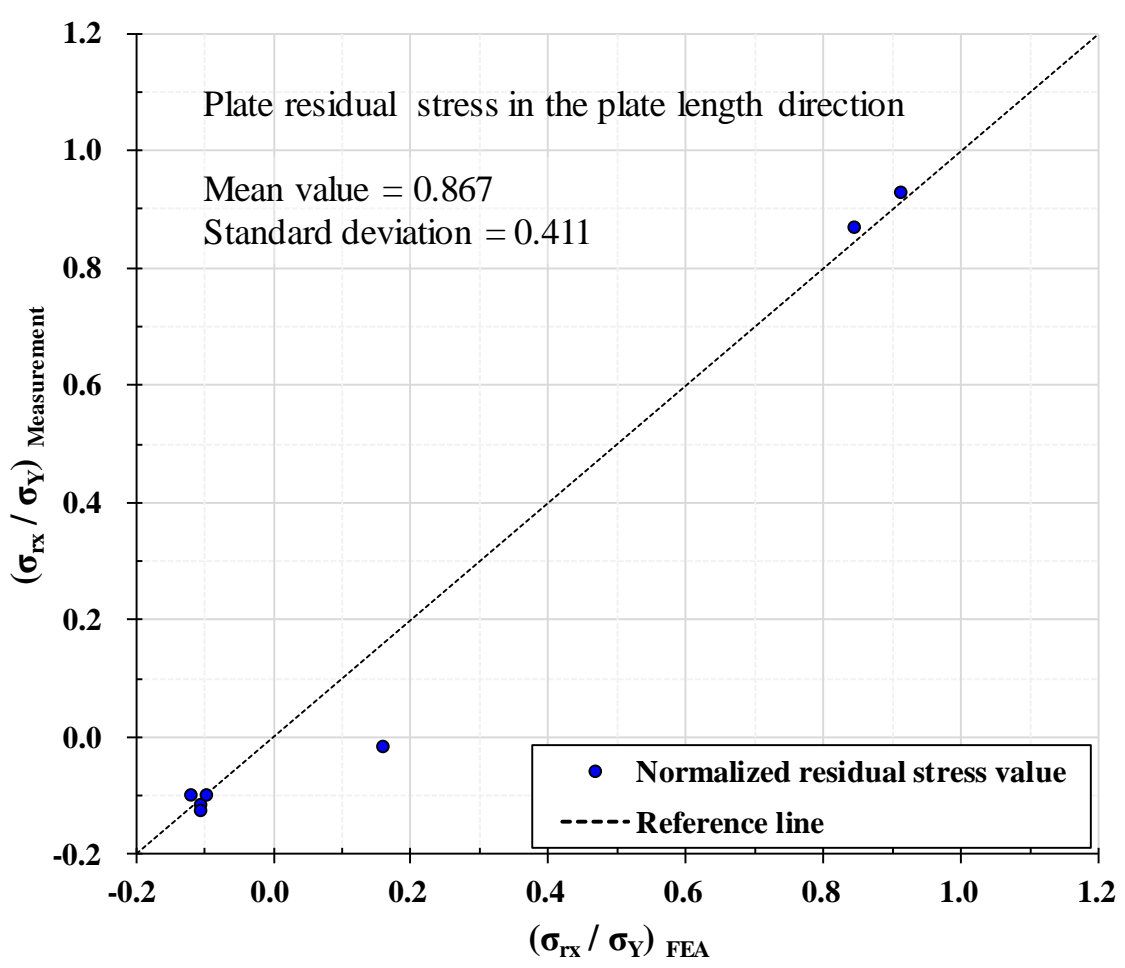

(a)

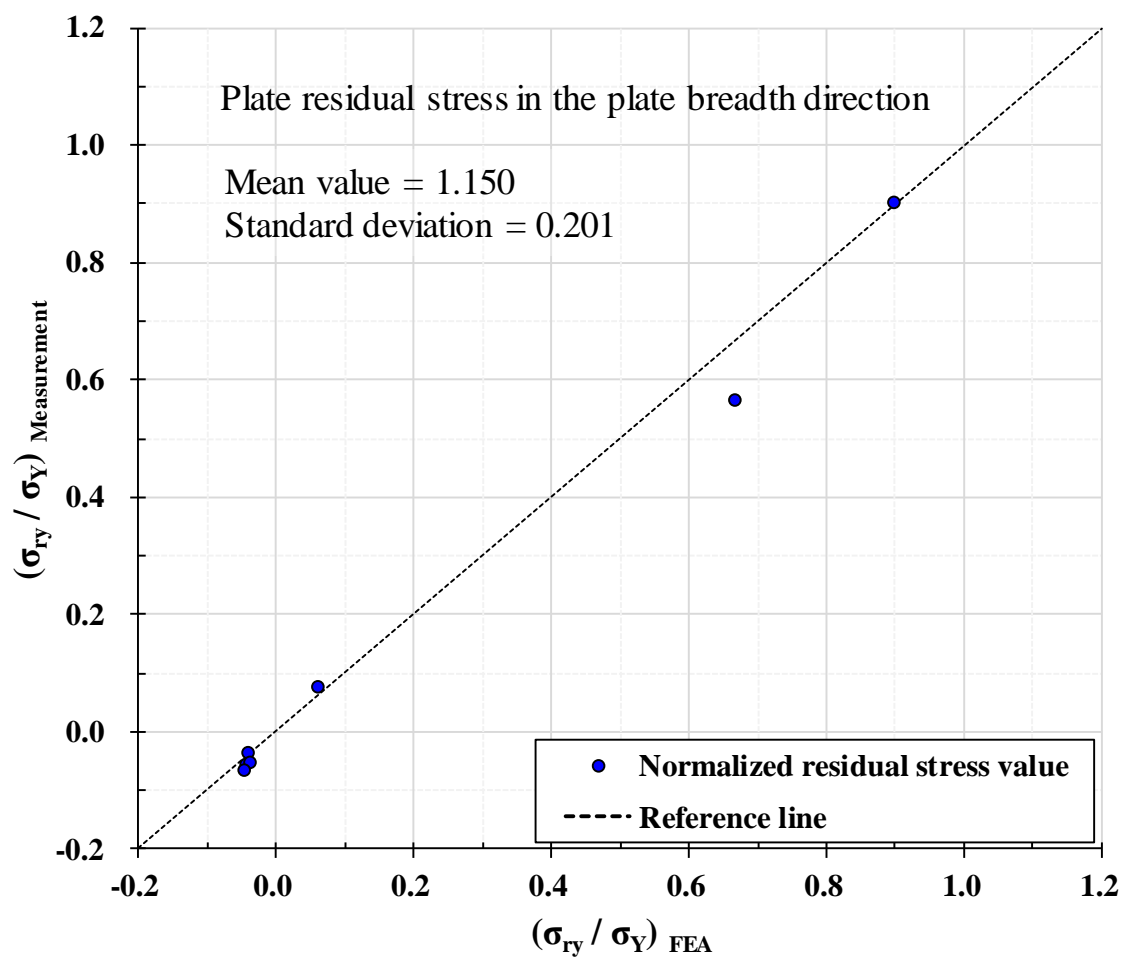

(b)

Figure 20. Statistical analysis of the plate residual stresses in (a) plate length (longitudinal) direction, (b) the plate breadth (transverse) direction. 


\section{Simple formula estimations of welding-induced residual stresses}

Simple formulations are useful to quickly estimate welding-induced residual stresses in steel stiffened plate structures. For that purpose, empirical formulations $[3,4]$ were used.

The distribution of welding-induced residual stresses in both directions was modeled with rectangular type of tensile and compressive residual stress blocks as shown in Figure 3. It is noted that buckling and ultimate compressive strength of plate elements is directly affected by compressive residual stresses rather than tensile residual stresses. In this case, the compressive residual stresses can be defined from the equilibrium conditions as follows [3]:

$$
\begin{gathered}
\sigma_{r c x}=\frac{2 b_{t}}{2 b_{t}-b} \sigma_{r t x} \\
\sigma_{r c y}=\frac{2 a_{t}}{2 a_{t}-a} \sigma_{r t y}
\end{gathered}
$$

where $b_{t}$ and $a_{t}$ are the breadth of tensile residual stress block in the plate breadth or length direction, respectively, $\sigma_{r t x}, \sigma_{r t y}$ are the magnitude of tensile residual stress block in the plate length or breadth direction, respectively, $\sigma_{r c x}, \sigma_{r c y}$ are the magnitude of compressive residual stress block in the plate length or breadth direction, respectively, $a$ is the plate length (spacing between transverse frames), and $b$ is the plate breadth (spacing between longitudinal stiffeners). $\sigma_{r t x}$ and $\sigma_{r t y}$ are approximately equal to $\sigma_{Y}$ (material yield strength) for structural steels.

Equation (1) reveals that the compressive residual stresses can be estimated once the breadths of tensile residual stress blocks are defined. Empirical formulations of $b_{t}$ and $a_{t}$ were developed as a function of the weld leg length $L_{w}$ as follows [3, 4]:

$$
b_{t}=c_{1} \times L_{w}+c_{2}
$$

where, $c_{1}=-0.4562 \times \beta_{x}^{2}+4.1994 \times \beta_{x}+2.6354$,

$$
\begin{gathered}
c_{2}=1.1352 \times \beta_{x}^{2}-4.3185 \times \beta_{x}-11.1750 \text { and } \beta_{x}=\frac{b}{t} \sqrt{\frac{\sigma_{Y}}{E}} . \\
a_{t}=d_{1} \times L_{w}+d_{2}
\end{gathered}
$$

where, $d_{1}=-0.0399 \times \beta_{y}^{2}+2.0087 \times \beta_{y}+8.7880$,

$$
d_{2}=-0.1042 \times \beta_{y}^{2}-4.8575 \times \beta_{y}-17.7950 \text { and } \beta_{y}=\frac{a}{t} \sqrt{\frac{\sigma_{Y}}{E}} .
$$


Using Equations (1) - (3), the magnitude of compressive residual stresses in the longitudinal and transverse directions can be estimated. The yield strength of material AH32 is $331 \mathrm{MPa}$ and thus $\sigma_{Y}=\sigma_{r t x}=\sigma_{r t y}=331 \mathrm{MPa}$ is taken. Also, the leg length for the applied weld condition is $L_{w}=7 \mathrm{~mm}$. Therefore, the slenderness ratios are obtained as $\beta_{x}=2.88$ and $\beta_{y}=12.63$. Equations (2) and (3) then provide the breadths of tensile residual stress blocks as follows:

$$
\begin{gathered}
c_{1}=-0.4562 \times \beta_{x}^{2}+4.1994 \times \beta_{x}+2.6354 \\
=-0.4562 \times 2.88^{2}+4.1994 \times 2.88+2.6354=10.9575 \\
c_{2}=1.1352 \times \beta_{x}^{2}-4.3185 \times \beta_{x}-11.1750 \\
=1.1352 \times 2.88^{2}-4.3185 \times 2.88-11.1750=-14.1797 \\
b_{t}=c_{1} \times L_{w}+c_{2}=51.5655 \mathrm{~mm} \\
d_{1}=-0.0399 \times \beta_{y}^{2}+2.0087 \times \beta_{y}+8.7880 \\
=-0.0399 \times 12.63^{2}+2.0087 \times 12.63+8.7880=27.7960 \\
d_{2}=-0.1042 \times \beta_{y}^{2}-4.8575 \times \beta_{y}-17.7950 \\
=-0.1042 \times 12.63^{2}-4.8575 \times 12.63-17.7950=-95.7883 \\
a_{t}=d_{1} \times L_{w}+d_{2}=70.9877 \mathrm{~mm}
\end{gathered}
$$

Ultimately, the compressive residual stresses in the longitudinal and transverse directions were estimated from Equation (1) as follows:

$$
\sigma_{r c x}=-55.34 \mathrm{MPa}, \sigma_{r c y}=-14.92 \mathrm{MPa}
$$

Figure 21 compares the welding-induced residual stresses between direct measurements, numerical computations and simple formula estimations. It is found that the difference of the average compressive residual stresses between direct measurements and simple formula estimations is about $10 \%$. 


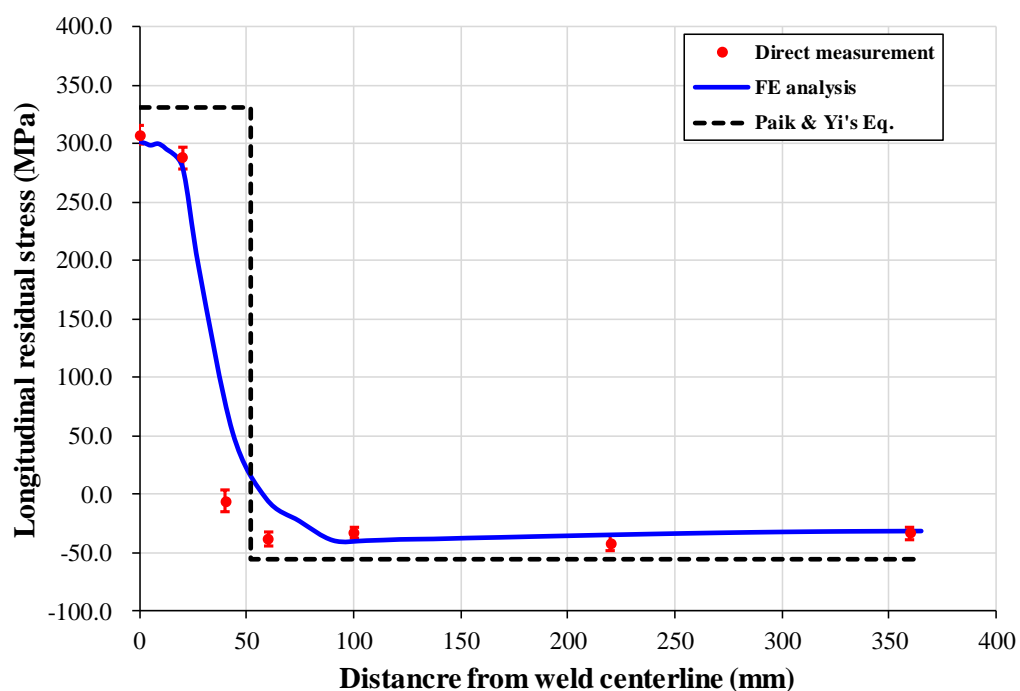

(a)

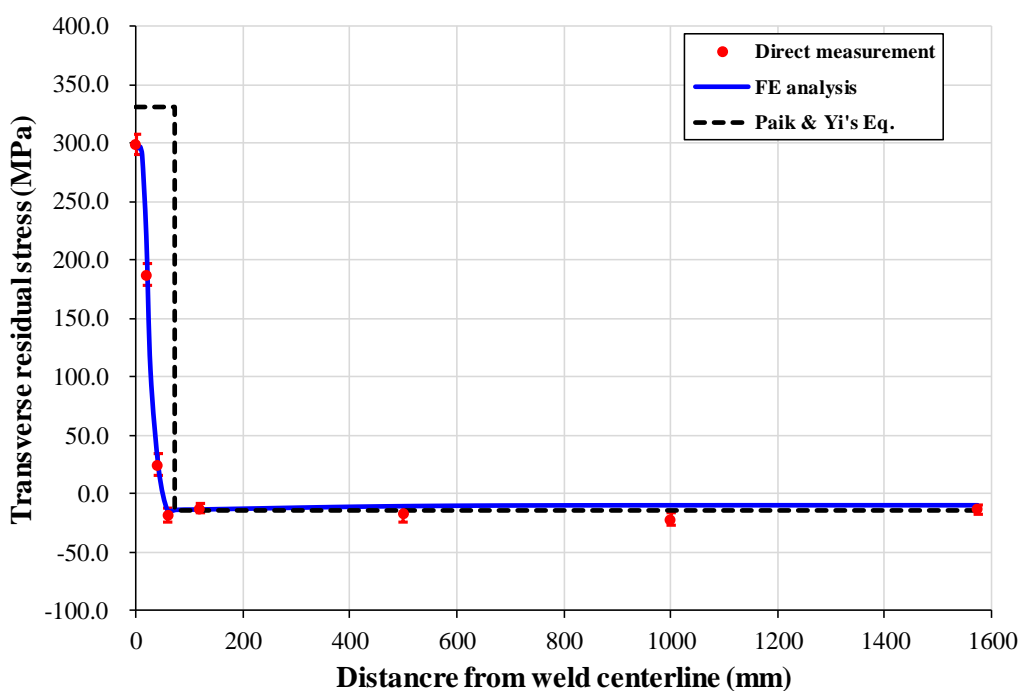

(b)

Figure 21. A comparison of welding-induced residual stresses between direct measurements, numerical predictions and simple formula estimations.

\section{Concluding remarks}

The aim of the paper was to obtain measurement data of welding-induced residual stresses in a full-scale steel stiffened plate structure. Computational models for their numerical predictions together with simple formula estimations were also presented. Based on the studies, the following conclusions can be drawn.

(1) A full-scale steel stiffened plate structure associated with bottom plate panels of an as-built containership carrying 1,900 TEU was successfully designed and fabricated in a shipyard, Busan, South Korea which has built small and medium sized merchant and patrol ships.

(2) Exactly the same technology of welding as used in today's shipbuilding industry was applied for fabrication of the structure following the classification society rules and welding procedure specifications. Full penetration of weld material along weld lines of fillet welding was secured to 
attach support members to plating with a welding leg length of $7 \mathrm{~mm}$.

(3) As a non-contact technique, the X-ray diffraction method was employed to measure the welding-induced residual stress distributions of the structure within acceptable errors of measurements.

(4) Computational models using three-dimensional thermo-elastic-plastic finite element method were developed to predict the welding-induced residual stress distributions of the tested structure. It is found that the numerical predictions are in good agreement with direct measurements.

(5) Simple formulations [3, 4] were used to estimate welding-induced residual stresses. It is confirmed that the estimations agree reasonably well with the measured residual stresses.

\section{Acknowledgements}

This work was conducted at the International Centre for Advanced Safety Studies / the Korea Ship and Offshore Research Institute (www.icass.center) which has been a Lloyd's Register Foundation Research Centre of Excellence since 2008.

\section{ORCID}

Jeom Kee Paik: http://orcid.org/0000-0003-2956-9359

\section{References}

[1] Yi MS, Lee DH, Lee HH, Paik JK. Direct measurements and numerical predictions of welding-induced initial deformations in a full-scale steel stiffened plate structure. Accepted for publication in Thin-Walled Structures; 2020.

[2] Ueda Y. Computational welding mechanics (A volume of selected papers in the commemoration of the retirement from Osaka University). Joining and Welding Research Institute, Osaka, Japan; 1999.

[3] Paik JK. Ultimate limit state analysis and design of plated structures, 2nd Edition. Chichester: John Wiley \& Sons; 2018.

[4] Yi MS, Hyun CM, Paik JK. An empirical formulation for predicting welding-induced biaxial compressive residual stresses on steel stiffened plate structures and its application to thermal plate buckling prevention. Ships and Offshore Structures 2019;14(S1):S18-S33.

[5] Masubuchi K. Analysis of welded structures: residual stresses, distortion and their consequences. Oxford: Pergamon Press; 1980.

[6] Smith CS, Davidson PC, Chapman JC, Dowling PJ. Strength and stiffness of ships' plating under in-plane compression and tension. Transactions of the Royal Institution of Naval Architects 1988;130:277-96.

[7] Paik JK, Pedersen PT. A simplified method for predicting the ultimate compressive strength of ship panels. International Shipbuilding Progress 1996;43:139-57.

[8] Paik JK, Thayamballi AK, Ryu JY, Jang JH, Seo JK, Park SW, Seo SK, Andrieu C, Cojeen HP, Kim NI. The statistics of weld induced initial imperfections in 
aluminium stiffened plate structures for marine applications. International Journal of Maritime Engineering 2006;148(Part A1):19-63.

[9] Paik JK, Andrieu C, Cojeen HP. Mechanical collapse testing on aluminium stiffened plate structures for marine applications. Marine Technology 2008;45(4):228-40.

[10] Paik JK, Kim DK. Advanced method for the development of an empirical model to predict time-dependent corrosion wastage. Corrosion Science 2012;63:51-58.

[11] Paik JK, Kim BJ, Sohn JM, Kim SH, Jeong JM, Park JS. On buckling collapse of a fusion-welded aluminium stiffened plate structure: An experimental and numerical study. Journal of Offshore Mechanics and Arctic Engineering 2012;134:021402.1-8.

[12] Paik JK. Practical techniques for finite element modeling to simulate structural crashworthiness in ship collisions and grounding (Part I: Theory). Ships and Offshore Structures 2007;2(1):69-80.

[13] Paik JK. Practical techniques for finite element modeling to simulate structural crashworthiness in ship collisions and grounding (Part II: Verification). Ships and Offshore Structures 2007;2(1):81-85.

[14] Paik JK. Characteristics of welding induced initial deflections in welded aluminium plates. Thin-Walled Structures 2007;45:493-501.

[15] Paik JK. Mechanical collapse testing on aluminium stiffened panels for marine applications. Ship Structure Committee, SSC-451, Washington, DC; 2008.

[16] Vhanmane S, Bhattacharya B. Estimation of ultimate hull girder strength with initial imperfections. Ships and Offshore Structures 2008;3(3):149-58.

[17] Luís RM, Guedes, Soares C, Nikolov PI. Collapse strength of longitudinal plate assemblies with dimple imperfections. Ships and Offshore Structures 2009;3(4):359-70.

[18] Bruno G, Yordan G, Guedes, Soares C. Effect of weld shape imperfections on the structural hot-spot stress distribution. Ships and Offshore Structures 2011;6(1-2):145-59.

[19] Khan I, Zhang S. Effects of welding-induced residual stress on ultimate strength of plates and stiffened panels, Ships and Offshore Structures 2011;6(4):297-309.

[20] Eggert L, Fricke W, Paetzhold H. Fatigue strength of thin-plated block joints with typical shipbuilding imperfections. Welding in the World 2012;56(11-12):119-28.

[21] Gannon LG, Liu Y, Pegg NG, Smith MJ. Effect of three-dimensional welding-induced residual stress and distortion fields on strength and behaviour of flat-bar stiffened panels, Ships and Offshore Structures 2012;8(5):565-78.

[22] Gannon LG, Pegg NG, Smith MJ, Liu Y. Effect of residual stress shakedown on stiffened plate strength and behaviour, Ships and Offshore Structures 2012;8(6):638-52.

[23] Gannon L, Liu Y, Pegg N, Smith MJ. Nonlinear collapse analysis of stiffened plates considering welding-induced residual stress and distortion, Ships and Offshore Structures 2015;11(3):228-44. 
[24] Khedmati MR, Pedram M, Rigo P. The effects of geometrical imperfections on the ultimate strength of aluminium stiffened plates subject to combined uniaxial compression and lateral pressure. Ships and Offshore Structures 2012;9(1):88-109.

[25] Teresa M, Craig F. Effect of weld-induced imperfections on the ultimate strength of an aluminium patrol boat determined by the ISFEM rapid assessment method. Ships and Offshore Structures 2013;9(2):218-235.

[26] Iranmanesh M, Azad N, Zabihpoor M. A new algorithm on welding process of T-shaped plates in ship hull structure to minimize distortion based on thermal simulation. Ships and Offshore Structures 2014;9(5):489-97

[27] Farajkhah V, Liu Y, Gannon L. Finite element study of 3D simulated welding effect in aluminium plates, Ships and Offshore Structures 2016;12(2):196-208.

[28] Fu G, Estefen SF, Gurova T, Lourenco MI. Effect of material model on residual stress and distortion in T-joint welding. Ships and Offshore Structures 2017;13(1):56-64.

[29] Lillemäe I, Liinalampi S, Remes H, Itävuo A, Niemelä A. Fatigue strength of thin laser-hybrid welded full-scale deck structure, International Journal of Fatigue 2017;95:282-92.

[30] Chen BQ, Hashemzadeh M, Guedes Soares C. Validation of numerical simulations with X-ray diffraction measurements of residual stress in butt-welded steel plates, Ships and Offshore Structures 2018;13(3):273-82.

[31] Matsui S. Control of weld distortion in thin-skin welded structures. Journal of Welding and Joining 1983;53(5):58-66.

[32] Cheng JJR, Elwi AE, Grodin GY, Kulak GL. Material testing and residual stress measurements in a stiffened steel plate. In: Strength and Stability of Stiffened Plate Components. Ship Structure Committee, SSC-399, Washington, DC; 1996.

[33] Kenno SY, Das S, Kennedy J, Rogge R, Gharghouri M. Distributions of residual stresses in stiffened plates with one and two stiffeners. Ships and Offshore Structures 2010;5(3):211-25.

[34] Kenno SY, Das S, Rogge RB, Gharghouri M. Changes in residual stresses caused by an interruption in the weld process of ships and offshore structures. Ships and Offshore Structures 2017;12(3):341-359.

[35] Paik JK, Lee MG, He KH, Lee SY, Thomas G. A full-scale physical model testing on the ultimate limit states of a steel stiffened plate structure under lateral patch loading in fires without passive fire protection. Busan, South Korea: The Korea Ship and Offshore Research Institute (Lloyd's Register Foundation Research Centre of Excellence); 2020.

[36] Paik JK, Lee MG, He KH, Lee SY, Thomas G. A full-scale physical model testing on the ultimate limit states of a steel stiffened plate structure under lateral patch loading in fires with passive fire protection. Busan, South Korea: The Korea Ship and Offshore Research Institute (Lloyd's Register Foundation Research Centre of Excellence); 2020.

[37] Paik JK, Lee DH, Noh SH, Park DK, Ringsberg JW. A full-scale physical model testing on the ultimate limit states of a steel stiffened plate structure under cyclic 
compressive loading. Busan, South Korea: The Korea Ship and Offshore Research Institute (Lloyd's Register Foundation Research Centre of Excellence); 2020.

[38] Paik JK, Lee DH, Park DK, Ringsberg JW. A full-scale physical model testing on the ultimate compressive limit states at cryogenic condition triggered by brittle fracture. Busan, South Korea: The Korea Ship and Offshore Research Institute (Lloyd's Register Foundation Research Centre of Excellence); 2020.

[39] Paik JK, Lee DH, Park DK, Ringsberg JW. A full-scale physical model testing on the ultimate compressive limit states of a steel stiffened plate structure at a temperature of $-100^{\circ} \mathrm{C}$. Busan, South Korea: The Korea Ship and Offshore Research Institute (Lloyd's Register Foundation Research Centre of Excellence); 2020.

[40] ASTM E8/E8M-09. Standard test methods for tension testing of metallic materials. PA (USA): ASTM International; 2011.

[41] DNV-GL Rules for classification - ships. Part 2 Materials and welding, Chapter 4 Fabrication and testing. Høvik(Norway): DNV-GL; 2017.

[42] Xstress 3000 Manual. Finland: Stresstech Inc; 2010.

[43] Yi MS, Hyun CM, Paik JK. Three-dimensional thermo-elastic-plastic finite element method modeling for predicting weld-Induced residual stresses and distortions in steel stiffened-plate structures. World Journal of Engineering and Technology 2018;6:176-200. 